\title{
Avaliação Morfométrica de Eqüinos da Raça Mangalarga Marchador: Medidas Angulares ${ }^{1}$ \\ Grasiele Coelho Cabral ${ }^{2}$, Fernando Queiroz de Almeida ${ }^{3}$, Pedro Cezar Nehme de Azevedo4, Célia Raquel Quirino ${ }^{5}$, Edson Mauro Santos ${ }^{6}$, Anderson Corassa ${ }^{7}$, Luís Fernando Batista Pinto ${ }^{7}$
}

RESUMO - Objetivou-se, com este trabalho, avaliar as medidas angulares de eqüinos em crescimento, do nascimento até os 12 meses de idade, e de animais adultos da raça Mangalarga Marchador. Foram avaliadas 11 medidas angulares de 98 animais (55 machos e 43 fêmeas) ao nascimento e a cada 30 dias até completarem 12 meses de idade. Os valores foram submetidos à análise de variância e o modelo estatístico incluiu os efeitos de sexo, de região, de manejo nutricional, de rebanho, de mês e de ano de nascimento, que, por sua vez, não influenciaram as variáveis estudadas. Os valores das angulações variaram em função do crescimento, não evoluindo linearmente no decorrer do período estudado. Os valores aumentaram e diminuíram a cada mensuração, talvez em função do crescimento desigual dos ossos envolvidos nestas angulações. Os valores médios observados para a angulação escápulo-solo variaram de 58,3 a $63,4^{\circ}$, nos machos, e de 58,1 a $63,1^{\circ}$, nas fêmeas, no período do nascimento aos 12 meses de idade, enquanto, nos animais adultos, o valor médio foi de $66,8^{\circ}$, tanto nos machos quanto nas fêmeas. Observou-se relativa concordância entre as aberturas dos ângulos anteriores e posteriores, quando comparados os valores dos ângulos escápulo-umeral e coxo-femural, úmero-radial e fêmur-tibial, metacarpo-falangeano, tíbio-metatarsiano e metatarsofalangeano. No membro anterior, houve variação diretamente proporcional das aberturas dos ângulos escápulo-solo e escápulo-umeral, enquanto, no membro posterior, a variação foi inversamente proporcional entre os ângulos coxal-solo e coxo-femural.

Palavras-chave: angulação, crescimento, mensuração, potras, potros

\section{Morfometric Evaluation of Mangalarga Marchador Horses: Angular Measures}

ABSTRACT - This work was carried out to evaluate angular measures of foals, from birth to 12 months age, and mature animals of the Mangalarga Marchador horse. Eleven angular measures of 98 foals, 55 males and 43 females, were taken on the birth day and at each thirty days up to complete 12 months of age. Results of measures were submitted to analysis of variance and mathematical model included effects of sex, region, nutritional management, herd, month and year of birth. The variables studied were not influenced by sex, herd, nutritional management, month and year of birth. The values increases and decreases at each month, what can be result of unequal growth of bones that form the angles. Average values observed for shoulder-floor angle of foals varied from 58.3 to $63.4^{0}$, for males, and from 58.1 to $63.1^{\circ}$, for females. The average value of shoulder-floor angle was $66,8^{\circ}$ for stallions and mares. There were observed a relative agreement between the angles of anterior and posterior legs comparing values of angles shoulder-humerus with coxae-femur, humerus-radius with femur-tibia, metacarpus-phalanx with metatarsus-phalanx and tibia-metatarsus with metatarsus-phalanx. In anterior leg was observed variation directly proportional of the angles shoulder-floor and shoulder-humerus, while in posterior leg the variation there were inversely proportional between the angles coxae-floor and coxae-femur.

Key Words: angle, fillies, foals, growth, measurement

\section{Introdução}

A raça Mangalarga Marchador é uma das mais importantes do Brasil. Com andamento marchado, cômodo e imponente, possuidores de distinta beleza zootécnica e uma docilidade ímpar, os cavalos Mangalarga Marchador vêm conquistando admiradores, que logo se tornam criadores, proporcionando a expansão da raça nos mercados nacional e internacional.

Considerando o Mangalarga Marchador como cavalo de sela, por apresentar andamento marchado, as medidas angulares dos raios ósseos das principais articulações envolvidas na dinâmica do andamento

\footnotetext{
${ }^{1}$ Parte da Dissertação do primeiro autor apresentada ao Programa de Pós-graduação em Zootecnia da UFRRJ. Projeto financiado pela FAPERJ/ABCCMM.

2 Zootecnista. Mestre em Zootecnia - UFRRJ - Seropédica - RJ. E.mail: g.ccabral@bol.com.br

3 Professor Adjunto - UFRRJ. Bolsista de Pesquisa II do CNPq.

Correspondência: DMCV-IV-UFRRJ BR 465, Km 7. Seropédica, RJ, CEP: 23890-000. E.mail: falmeida@ufrrj.br

4 Professor Adjunto. DG-IB-UFRRJ BR 465, Km 7. Seropédica, RJ, CEP: 23890-000. E.mail: nehme@ufrrj.br

5 Professor Associado - LMGA-CCTA-UENF - Campos dos Goytacazes - RJ. E.mail: crq@uenf.br

${ }^{6}$ Discente de graduação em Zootecnia. Bolsista de Iniciação Científica PIBIC/CNPq - UFRRJ.

7 Discente de graduação em Zootecnia. Bolsista de Iniciação Científica FAPERJ.
} 
característico devem ser avaliadas, para melhor caracterização do padrão racial e do desenvolvimento dos potros desta raça.

A utilização das medidas das diversas partes anatômicas do animal como critério objetivo de avaliação da conformação tem longa história. No clássico trabalho "D'extérieur du cheval", Goubaux \& Barrier (1890) discutem a possibilidade de mensurar os ângulos dos cavalos a partir de fotografias obtidas de perfil. A vantagem seria que todos os ângulos, em uma foto, seriam registrados no mesmo momento, ao contrário de registros tomados diretamente nos animais.

Segundo Ribeiro (1988), nem todos os ângulos têm a mesma ação e efeito. Os de abertura anterior possuem forte ação nos movimentos do animal e, por isso, são chamados de impulsores, enquanto os de abertura posterior são denominados complementares ou de ligação. Dessa forma, para haver harmonia e equilíbrio nos andamentos, é necessário que estes ângulos, dos membros anteriores e posteriores, mantenham perfeita concordância nas respectivas aberturas e direções. Os membros anteriores estão relacionados à comodidade do andamento e os posteriores, ao rendimento do andamento. A função principal dos locomotores dianteiros é suportar o peso, absorver choques e levantar o animal do solo durante o seu deslocamento, enquanto os locomotores posteriores proporcionam a impulsão principal. Portanto, o locomotor posterior é projetado para empurrar o corpo para frente, paralelo ao solo, ao passo que o locomotor dianteiro tem a função dupla de empurrar e alçar (Toledo, 1985).

Lage (2001), ao avaliar a qualidade da marcha de animais adultos da raça Mangalarga Marchador, segundo sua morfometria, seus aprumos e seu padrão de deslocamento, observou que as medidas corporais e as angulações ósseas dos membros do cavalo estão intimamente relacionadas ao tipo e à qualidade de seu andamento.

As articulações entre espádua e braço, braço e antebraço, coxa e perna, como também as regiões das quartelas e dos jarretes, têm sua maior ou menor eficiência determinada pela medida da angulação de cada uma destas regiões (Naves, 1995). Segundo Andrade (1986), no caso específico dos cavalos marchadores, a angulação escápulo-solo deve apresentar valores de 50 a $55^{\circ}$, e estes mesmos valores deverão ser observados na angulação falange-solo anterior, para que o cavalo possa estar em perfeito equilíbrio dinâmico.
Objetivou-se, com o presente trabalho, avaliar as medidas angulares de potros do nascimento aos 12 meses de idade e de animais adultos da raça Mangalarga Marchador.

\section{Material e Métodos}

O experimento foi conduzido no período de agosto de 2000 a março de 2002, nos seguintes criatórios de cavalos da raça Mangalarga Marchador: Haras FB Arpoador, em Jesuítas, Rio de Janeiro, RJ; Haras do Corumbá, em Morro Azul, Vassouras, RJ; Fazenda Paraíso; Catimba e Haras Fomento, localizados em Sacra Família do Tinguá, Engenheiro Paulo de Frontin, RJ.

Foram utilizados 98 eqüinos (55 machos e 43 fêmeas) mensurados ao nascimento e a cada trinta dias até completarem 12 meses de idade. Os animais eram filhos de 14 diferentes garanhões, representantes das mais diversas linhagens da raça Mangalarga Marchador. O manejo nutricional e sanitário adotados foram descritos por Cabral et al. (2004).

As medidas foram obtidas utilizando-se artrogoniômetro e angulador de cascos e procedidas exclusivamente por um mesmo técnico. Os animais foram mensurados sempre do lado direito do corpo, posicionados em estação forçada, sobre piso de cimento, menos irregular possível e sem declividade.

As medidas angulares (Figura 1) dos raios ósseos foram avaliadas segundo Torres \& Jardim (1981), por meio de pontos marcados, com adesivos circulares de cor branca, no corpo do animal.

Angulação escápulo-solo: aferida apoiando-se o centro do artrogoniômetro no ponto determinado pelo encontro da escápula com o úmero, mantendo a haste fixa no sentido horizontal paralela ao solo e a haste móvel passando no ponto marcado na crista da escápula;

Angulação escápulo-umeral: aferida a partir do encontro da escápula com o úmero, com a haste fixa passando pelo ponto marcado na região mediana da linha que liga a ponta da escápula ao codilho e a haste móvel passando pelo ponto marcado na crista da escápula;

Angulação úmero-radial: aferida apoiando-se o centro do artrogoniômetro no ponto marcado na região mediana da linha que liga a ponta escápula ao codilho, com a haste fixa acompanhando paralelamente o antebraço no sentido vertical ao solo e haste móvel passando pelo ponto marcado no encontro da escápula com o úmero; 
Angulação metacarpo-falangeana: aferida apoiando-se o centro do artrogoniômetro no ponto marcado na região mediana do boleto, mantendo-se a haste fixa paralela ao metacarpo no sentido vertical ao solo e a haste móvel acompanhando paralelamente a face lateral da quartela e do casco;

Angulação falange-solo: aferida com o angulador de cascos, apoiando-se a sola do casco na base do angulador e a haste móvel do angulador na face frontal da muralha do casco, dividindo este ao meio.

Angulação coxal-solo: aferida apoiando-se o centro do artrogoniômetro na articulação dos ossos íleo e fêmur, mantendo-se a haste fixa no sentido horizontal paralela ao solo e haste móvel passando pela ponta do íleo;

Angulação coxo-femural: aferida com o centro do artrogoniômetro e a haste móvel na mesma posição anterior, levando-se a haste fixa até o ponto marcado na soldra;

Angulação fêmur-tibial: aferida apoiando-se o centro do artrogoniômetro no ponto marcado na soldra, com a haste fixa passando pelo ponto marcado na articulação dos ossos íleo e fêmur e a haste móvel passando pelo ponto marcado na região mediana do jarrete;

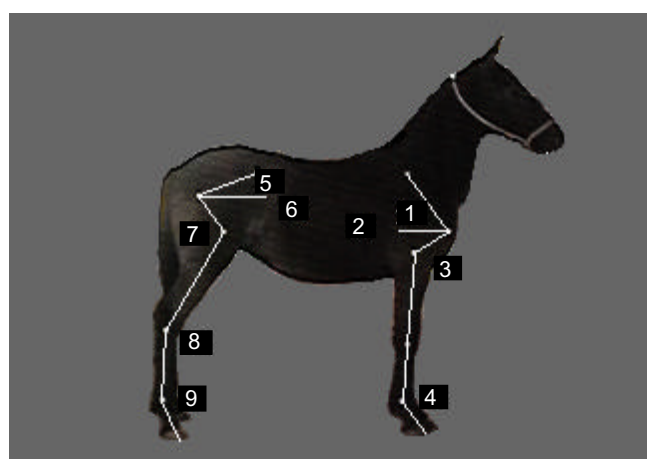

Figura 1 - Medidas de angulação escápulo-solo (1), escápulo-umeral (2), úmero-radial (3), metacarpo-falangeana (4), coxal-solo (5), coxofemural (6), fêmur-tibial (7), tíbio-metatarsiana (8) e metatarso-falangeana (9).

Figure 1 - Measures of shoulder-floor angle (1), shoulderhumerus (2), humerus-radius (3), metacarpusphalanx (4), coxae-floor (5), coxae-femur (6), femur-tibia (7), tibia-metatarsus (8) and metatarsus-phalanx (9).

R. Bras. Zootec., v.33, n.6, p.1790-1797, 2004 (Supl. 1)
Angulação tíbio-metatarsiano: aferida apoiando-se o centro do artrogoniômetro na região mediana do jarrete, mantendo-se a haste fixa no sentido vertical ao solo paralelamente ao osso metatarso e a haste móvel passando pelo ponto marcado na soldra;

Angulação metatarso-falageano: aferida apoiando-se o centro do artrogoniômetro no ponto marcado na região mediana do boleto, mantendo-se a haste fixa paralela ao metatarso no sentido vertical ao solo e a haste móvel acompanhando paralelamente a face lateral da quartela e do casco;

Angulação falange-solo: aferida com o angulador de cascos, apoiando-se a sola do casco na base do angulador e a haste móvel do angulador na face frontal da muralha do casco, dividindo este ao meio.

Os pais e as mães dos animais foram mensurados para obtenção dos valores médios das medidas angulares estudadas nos animais adultos. As médias dos machos e das fêmeas adultas foram utilizadas como base para calcular os valores percentuais dos potros e potras em relação à idade adulta.

Foi realizada a análise de consistência dos dados e a estatística descritiva das variáveis estudadas utilizando o procedimento PROC MEANS, FREQ do programa SAS (SAS, 1996). Os resultados das medidas corporais dos animais foram submetidos à análise de variância e foram testados os efeitos do sexo (macho e fêmea), do local de criação (regiões 1 e 2), do manejo nutricional (1 e 2), do rebanho de cada propriedade, do mês e ano de nascimento dos potros dentro de cada idade. Foi feita análise de variância dos dados dos animais adultos e a avaliação do efeito de sexo.

\section{Resultados e Discussão}

Os valores médios, desvios-padrão e percentuais em relação à idade adulta, observados para as medidas de angulação dos membros anteriores, dos machos e fêmeas, do nascimento aos 12 meses de idade, e dos animais adultos estão descritos nas Tabela 1. Os valores das angulações variaram em função do crescimento, não havendo, porém, crescimento linear das angulações no decorrer do período estudado. Os valores aumentaram e diminuíram a cada mensuração, talvez em função do crescimento desigual dos ossos envolvidos nessas angulações.

Os valores médios observados para a angulação escápulo-solo variaram de 58,3 a 63,4º, nos machos, e de 58,1 a $63,1^{\circ}$, nas fêmeas, do nascimento aos 12 
CABRAL et al.

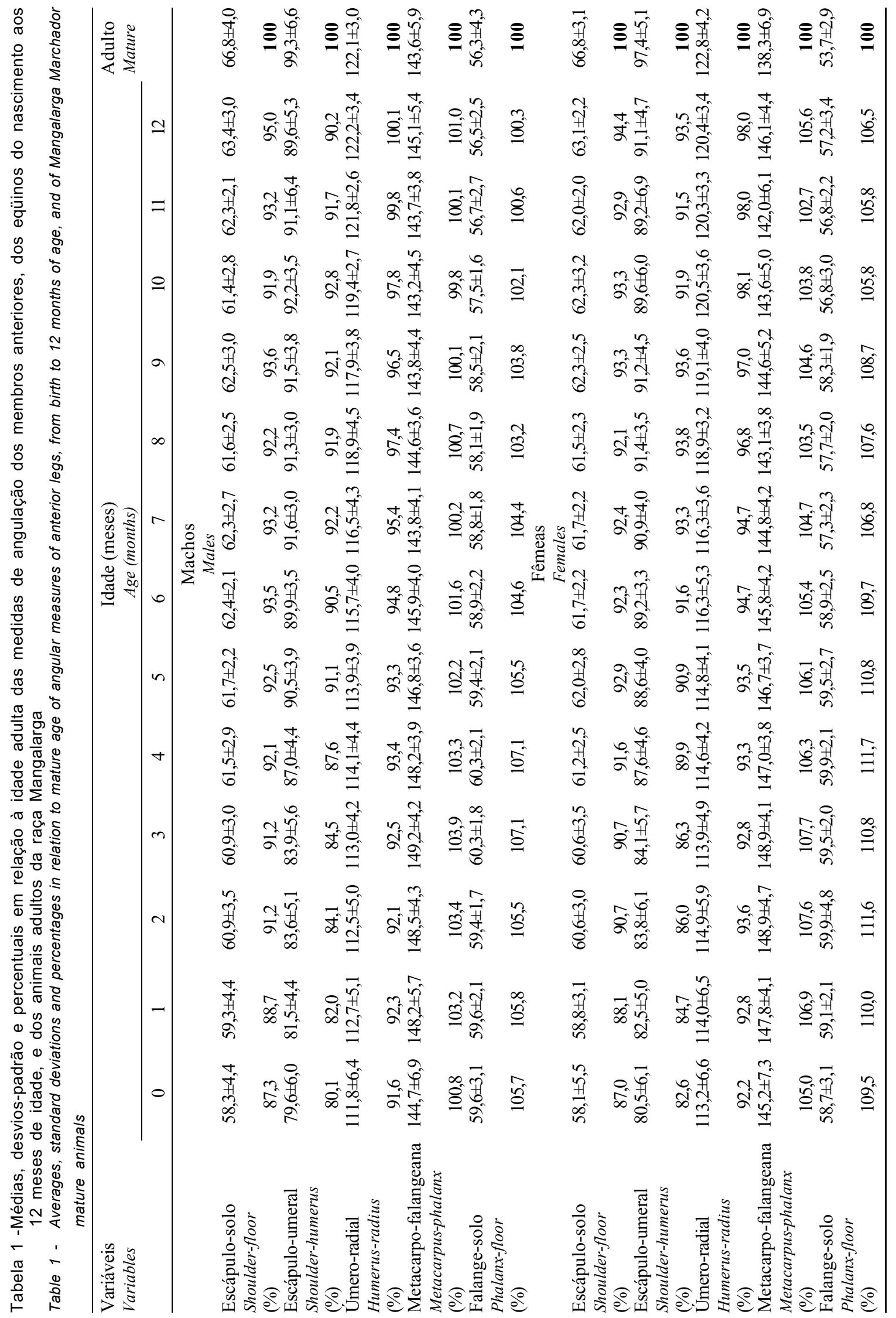

R. Bras. Zootec., v.33, n.6, p.1790-1797, 2004 (Supl. 1) 
meses de idade. Nos animais adultos, o valor médio observado para angulação escápulo-solo foi de $66,8^{\circ}$, tanto nos machos quanto nas fêmeas, acima dos valores de 50 a $55^{\circ}$, citados por Andrade (1986) como ideais para cavalos marchadores. No entanto, Lage (2001) observou valores variando entre 52 e $70^{\circ}$ para a angulação escápulo-solo, corroborando os resultados observados nesse estudo.

Quanto à angulação escápulo-umeral, os valores médios observados neste estudo variaram de 79,6 a $92,2^{\circ}$, do nascimento aos 12 meses, com média de $99,3^{\circ}$ à idade adulta, nos machos, e de 80,5 a $93,5^{\circ}$, do nascimento aos 12 meses, com média de $97,45^{\circ}$ à idade adulta, nas fêmeas-abaixo do mínimo de $102^{\circ}$, proposto por Torres \& Jardim (1981), para animais adultos de diferentes raças. Lage (2001) registrou valores de 80 a $135^{\circ}$, com média de $88,12^{\circ}$, em animais adultos da raça Mangalarga Marchador. Nascimento (1999), por sua vez, encontrou valores mais elevados (de 102 a $115^{\circ}$ ), em animais da mesma raça, enquanto Lazzeri (1992) verificou média de $90^{\circ}$, avaliando animais de diversas raças.

$\mathrm{Na}$ angulação úmero-radial, observaram-se valores médios de 111,8 a $122,2^{\circ}$, do nascimento aos 12 meses, de $122,1^{\circ}$ à idade adulta, nos machos, e nas fêmeas, entre 113,2 e $120,5^{\circ}$, do nascimento aos 12 meses, e de $122,8^{\circ}$ à idade adulta. O ângulo mínimo proposto por Torres \& Jardim (1981), para animais adultos de diferentes raças foi de $140^{\circ}$, ao contrário de Lage (2001), que observou mínimo de 118 e máximo de $155^{\circ}$, com média de $130,7^{\circ}$.

Os valores médios observados para angulação metacarpo-falangeana variaram de 143,2 a $149,2^{\circ}$, nos machos e entre 142,0 e $148,9^{\circ}$, nas fêmeas, do nascimento aos 12 meses de idade, enquanto as médias, nos animais adultos, foram de $143,6^{\circ}$ (machos) e de $138,3^{\circ}$ (fềmeas). O valor médio de $144,9^{\circ}$, obtido por Lage (2001), para a angulação metacarpo-falangeana foi semelhante aos valores médios observados neste estudo em todas as idades estudadas, tanto para os machos quanto para as fêmeas.

Os valores médios, desvios-padrão e percentuais em relação à idade adulta, observados para as medidas de angulação dos membros posteriores, dos machos e fêmeas, do nascimento aos 12 meses de idade, e dos animais adultos estão descritos nas Tabela 2 .

Os valores para angulação coxal-solo variaram, no período estudado, de 22,1 a $26^{\circ}$, nas fêmeas, e de
21,5 a $25,8^{\circ}$, nos machos, diferente dos observados por Lage (2001), que variaram de 40 a $60^{\circ}$, em animais adultos da mesma raça, discordância possivelmente explicada pela metodologia utilizada para a mensuração dessa característica, posto que não foram encontrados na literatura dados que pudessem ser comparativos.

Para angulação coxo-femural, os valores variaram de 69,9 a $83,0^{\circ}$, nos machos, e de 71,4 a $86,7^{\circ}$, nas fêmeas, do nascimento aos 12 meses de idade. Nos animais adultos, $o$ valor médio $\left(81,4^{\circ}\right)$ foi inferior ao mínimo para animais adultos de diferentes raças $\left(85^{\circ}\right)$, proposto por Torres \& Jardim (1981), superado pela média obtida nas fêmeas $\left(89,2^{\circ}\right)$.

A angulação fêmur-tibial apresentou variações de 101,0 a $118,1^{\circ}$, nos machos, do nascimento aos 12 meses de idade, com média à idade adulta de $120,6^{\circ}$, e entre 104,6 e $118,9^{\circ}$, nas fêmeas, do nascimento aos 12 meses de idade, com média à idade adulta de $120,1^{\circ}$, inferior ao mínimo $\left(122^{\circ}\right)$ proposto por Torres \& Jardim (1981), para animais adultos de diferentes raças.

Para a angulação tíbio-metatarsiana, os valores médios variaram de 144,3 a $150,3^{\circ}$, nos machos, e de 144,6 a $150,8^{\circ}$, nas fêmeas, do nascimento aos 12 meses de idade. As médias nos adultos foram de 149,9 e $146,3^{\circ}$, com desvios de 1,6 e $2,8^{\circ}$, nos machos e nas fêmeas, respectivamente.

Valores superiores foram citados por Lage (2001), que observou média de $154,4^{\circ}$, com desviopadrão de $5,7^{\circ}$, em animais adultos. Segundo a autora, houve grande variação desta característica em seus dados, em função da baixa precisão da mensuração, resultante do difícil acesso aos jarretes dos animais inquietos, dificuldade também observada neste experimento, sobretudo pelo uso de animais em crescimento, que ainda estavam sendo domados, mas que, por serem menores, eram mais fáceis de serem contidos.

Os valores médios observados para angulação metatarso-falangeana superaram os encontrados para a angulação metacarpo-falangeana, aproximadamente $1^{\circ}$, variando de 145,4 a $150,6^{\circ}$, nos machos, e de 146,7 a $151,6^{\circ}$, nas fêmeas, no período do nascimento aos 12 meses de idade. Nos animais adultos, a diferença entre as angulações dos membros anteriores e posteriores foi maior, apresentando, a angulação metatarsofalangeana, valores médios de $148,2^{\circ}$, nos machos e de $144,2^{\circ}$, nas fêmeas. 
CABRAL et al.

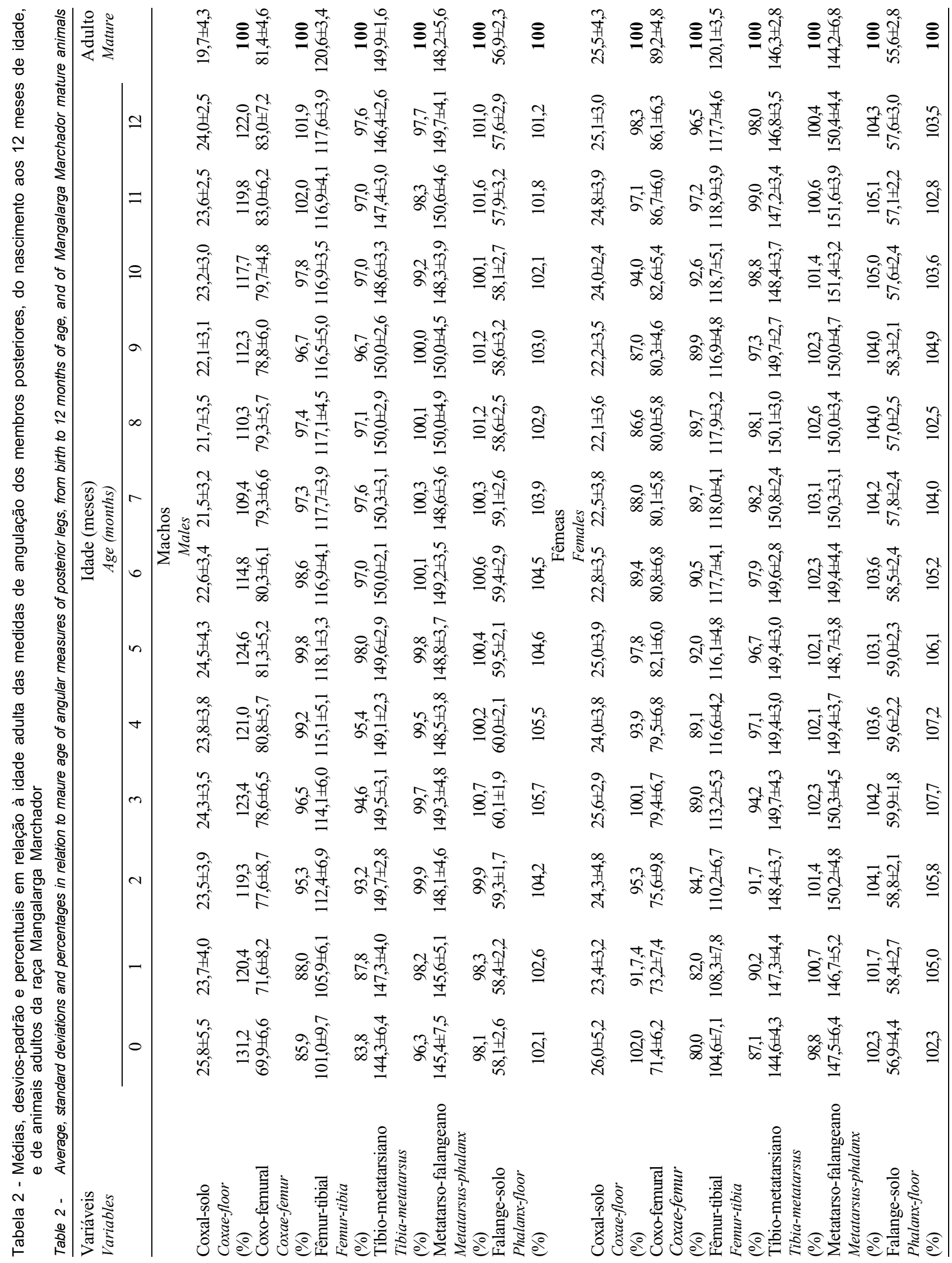

R. Bras. Zootec., v.33, n.6, p.1790-1797, 2004 (Supl. 1) 
Os valores médios registrados neste estudo para as angulações metacarpo-falangeana e metatarsofalangeana estão próximos do valor mínimo $\left(150^{\circ}\right)$ proposto por Torres \& Jardim (1981), para animais adultos de diferentes raças.

Os valores médios para as angulações falangesolo anterior e falange-solo posterior dos potros e potras, variaram de 56,8 a $60,3^{\circ}$, respectivamente. Nos animais adultos, variaram de 56,3 a $56,9^{\circ}$, nos machos, e de 53,7 a $55,6^{\circ}$, nas fêmeas. Lage (2001) relata valores semelhantes (de 40 a $70^{\circ}$ ) para angulação falange-solo (anterior e posterior), em animais adultos da raça Mangalarga Marchador.

Segundo Lage (2001), maiores angulações da falange com o solo evidenciam animais de membros mais verticalizados, o que pode estar relacionado à menor capacidade de amortecimento e andamentos mais ásperos. A mesma autora afirma que a equivalência dos membros anteriores e posteriores nos valores das angulações falange-solo permite que os arcos de elevação e descida dos membros durante o deslocamento gerem movimentos uniformes, que estão intimamente relacionados com a comodidade e o estilo do andamento.

De acordo com Andrade (1986), deve haver, nos animais marchadores, equivalência das angulações escápulo-solo e falange-solo anterior, sendo ideal variação de 50 a $55^{\circ}$ - afirmação não confirmada nesse estudo, pois os valores observados, tanto para angulação escápulo-solo como para as angulações falange-solo anterior e posterior, foram superiores aos citados por esse autor.

Houve relativa concordância entre as aberturas dos ângulos anteriores e posteriores, quando comparados os valores dos ângulos escápulo-umeral e coxo-femural, úmero-radial e fêmur-tibial, metacarpofalangeano, tíbio-metatarsiano e metatarsofalangeano. Este resultado concorda com Torres \&Jardim (1981), quando citam a necessidade desta relação para que o animal revele harmonia e regularidade nos seus andamentos.

Quanto ao membro anterior, observou-se variação diretamente proporcional das aberturas dos ângulos escápulo-solo e escápulo-umeral, enquanto, no membro posterior, houve variação inversamente proporcional entre os ângulos coxal-solo e coxofemural. Esse dado é importante, pois corresponde aos ângulos responsáveis pela comodidade e impulsão dos animais marchadores.
Deve-se lembrar que os potros foram avaliados do nascimento aos 12 meses de idade e os ossos envolvidos nestas angulações ainda não atingiram seu tamanho e direcionamento final.

\section{Conclusões}

As medidas angulares não apresentaram variações crescentes no período de crescimento, porém podem ser utilizadas para melhor observação do crescimento ósseo dos eqüinos e das mudanças ocorridas na conformação dos membros dos animais.

$\mathrm{O}$ fato de apresentarem pequena variação do nascimento à idade adulta demonstra que as medidas angulares podem ser utilizadas na avaliação fenotípica e na seleção dos animais jovens com elevado grau de segurança e confiabilidade, constituindo importante ferramenta para a seleção e o melhoramento genético dos animais da raça Mangalarga Marchador.

\section{Agradecimento}

À FAPERJ e a ABCCMM, pelo apoio financeiro, e aos criadores Francismar Barbieri, Luiz Antônio Wanderlei, Hélio Belo Cavalcanti, João de Biasi, Maria Irene Batista dos Reis e Mário Freire Neto, proprietários dos criatórios participantes do experimento, por disponibilizarem seus animais.

\section{Literatura Citada}

ANDRADE, L.S. O condicionamento do cavalo no Brasil - trabalho, competição, reprodução. Recife: Art 3, 1986. $201 \mathrm{p}$.

CABRAL, G.C.; ALMEIDA, F.Q.; QUIRINO, C.R. et al. Avaliação morfométrica de eqüinos da raça Mangalarga Marchador: medidas lineares. Revista Brasileira de Zootecnia, v.33, n.4, p.989-1000, 2004.

GOUBAUX, A.E.; BARRIER, G. De l'exterior du cheval. 2.ed. Paris: Asselin, 1890. 996p.

LAGE, M.C.G.R. Caracterização morfométrica, dos aprumos e do padrão de deslocamento de eqüinos da raça Mangalarga Marchador e suas associações com a qualidade da marcha. Belo Horizonte: Universidade Federal de Minas Gerais, 2001. 114p. Tese (Doutorado em Ciência Animal) - Universidade Federal de Minas Gerais, 2001.

LAZZERI, L. Lições de podologia eqüina. Belo Horizonte: Universidade Federal de Minas Gerais, 1992. 224p.

NASCIMENTO, J.F. Mangalarga Marchador: tratado morfofuncional. Belo Horizonte: Associação Brasileira dos Criadores do Cavalo Mangalarga Marchador, 1999. $577 \mathrm{p}$.

NAVES, R.C. Interpretação do padrão racial. Escola Nacional de Árbitros. ABCCMM, 1995. np. 
RIBEIRO, D.B. O cavalo: raças, qualidades e defeitos. Rio de Janeiro: Globo, 1988. 318p.

STATISTICAL ANALYSIS SYSTEM - SAS. SAS users's guide: statistical. version 6. Cary: 1996.

TOLEDO, A.P. Mecânica de sustentação e locomoção dos eqüinos. São Paulo: Panamed, 1985. 177p
TORRES, A.P.; JARDIM, W.R. Criação do cavalo e de outros eqüinos. São Paulo: Nobel, 1981. 654p.

Recebido em: 02/05/03 Aceito em: 30/03/04 